Prog. Neuro-Psychopharmacol. Vol.4, pp.585-590.

$0364-7722 / 81 / 0101-0545 \$ 05.00 / 0$

Pergamon Press Ltd, 1981. Printed in Great Britain.

\title{
DOPAMINERGIC INVOLVEMENT IN ATTENTION A NOVEL ANIMAL MODEL 1
}

\author{
R.J. KATZ and K. SCHMAL'TZ \\ Mental Health Research Institute, Department of Psychiatry \\ University of Micnigan Medical Center, Ann, Arbor, Michigan
}

(Final form, August 1980)

\begin{abstract}
1. Adult male outbred albino mice were acutely injected with either of two dopamine (DA) agonists; Aponorpinine, a receptor agonist, or Amantadine, a DA releasing agent.

2. Both drugs produced dose-related alterations in initial Y-maze behavior, consisting of significantly increased proportions of 2-arin entries.

3. This behavior has previously been shown to reflect an abnormal attentional process.

4. Thus DA activation may cause sensory perseveration.

5. The implications of this finding for DA theories of psychopatiology is discussed.
\end{abstract}

Key-words: amantadine, apomorphine, attention, dopamine, sensory perseveration, stereotypy

\section{Introduction}

The actions of amphetamines and related psychostinulants are behaviorally and biochemically complex. One effect which may be found in a variety of species, however, involves the elicitation of repetitive and highly invariant motor syndromes which often lack a well defined goal (i.e. motor stereotypes; Randrup and Munkvad, 1967). Stereotyped behavior is of interest for a number of reasons. Its neurochemical and neuroanatomical substrates are reasonably well defined and primarily involve the nigroneostriatal dopamine containing system (Fog, 1972; Iversen, 1977). Stereotypy, therefore, is a useful model for exploring brain-behavior relations. Moreover, stereotypy may bear a functional relationship to human psychopatholoyical conditions including possibly schizophrenia (Meltzer and stahl, 1976).

While the predominant view of stereotypy suggests it involves the abnormal activation of a motor substrate, this may be a simplification. Reports from a number of laboracories have pointed to a role for sensory processes and sensory-motor interactions in the determination of behaviors elicited by

I This research was carried out in partial fulfillment of an underyraduate honor's requirement in biology by the second author. Dr. Katz is a Sloan Foundation Fellow in neuroscience. 
amphetamines. Stevens (Stevens et al., 1977) elicited striking examples of motor stereotypy in cats, and these were abolished by reducing normal visual information. Isaac (1971) has suggested an interaction of anphetamines with lighting conditions in rats and Kokkinidis and Anisman (1977, 1978) investigated sensory mediation and motor control of $Y$ maze behavior of normal and amphetamine pre-treated mice.

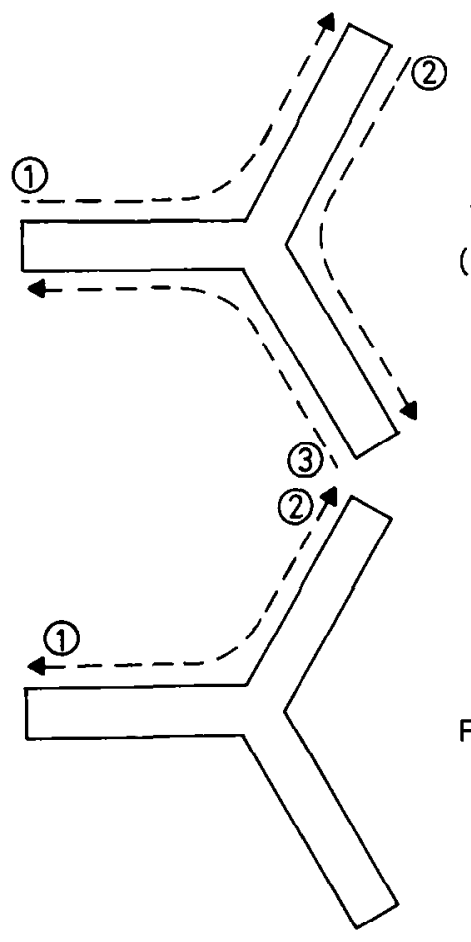

\section{A}

Turning Bias

(Motor Effect)

B

Attentional

Perseveration

\section{Y MAZE RESPONSES}

Figure 1: Two response patterns of mice in a $Y$ maze: A) Sensory alternation (response perseveration) is most typically seen with initial exploration; B) Sensory perseveration (response alternation) is most typically seen after psychostimulants or dopamine agonists.

The equiangular $Y$ maze allows a dissociation of two factors in amphetamine (and other drug) induced behaviors. If a drug induces a motor bias, such as turning, as has been reported by Glick and co-workers (1977), then a consistent motor pattern will cause sequential rotation throughout the three arms of the maze (Fig. IA). If on the other hand, a drug treatment causes an alternation in attention ( 1 .e. a tendency to perseverate among a few stimuli) then only two of three arms of the maze (those to which attention is focused) will be predominantly entered (Fig. lB). Generally undrugged behaviors involve both tendencies although entries into all arms are the most typical initial pattern of behavior, reflecting sensory alternation, and possibly contributions of motor bias (Kokkinidis and Anisman, 1977). Amphetamines 
significantly increase repedied two-arm entries.

We empnasize that although an alternating (three-arin) pattern may by due to etther of che above explanations (motor bias, sensory alternacion), the converse pattern (repeated two-arm entries) cannot be readily explained by these factors. Two-arm perseveration demands alternating right and left motor responses, so it is not a simple scereorype. Further, additional experiments directly inplicate sensory factors in the amphelamine induced perseveration responses since (a) they may be interrupted by sufficiently salient sensory scimulation of a novel nature (Kokkinidis and Anisman, 1979) and (b) conversely, they may be facilitated by habituation (Kokkinidis and Anisman, 1977). The Y-maze task therefore represents a potentially useful tool for the examination of an alteration in atcentional processes. Aside from the already mentioned studies on amphetanines, no systematic study has been carried out utilizing DA active drugs.

The present investigation was prompted in part by the studies upon amphetanines and in part by the theoretical nodel of psychosis developed by Ellinwood (Ellinwood et al., 1973) which also suggested a role for attentional processes in the mediation of ampinetamine syndromes. Since amphetamines may act through dopamine (DA; see Iversen, 1977), we examined whether it mignt be possible to airectly implicate DA in the pathological attentional behaviors described by kokkinidis. Any such implication would be of particular interest $\mathrm{g}$ iven both the potential involvement of dopamine in schizophrenia (Crow et al., 1975; Stevens, 1977; Carlsson, 1978) and the need to develop animal models involving attentional processes (Mirsky and orren, 1978). In the present study we examined the $Y$-maze performance of nice after dopaninergic stimulation by two methods.

\section{Methods}

Forty one adult inale Swiss-Webster mice (25-30 g body weight) were group noused with food (Teklad 4.0 fat rodent diet) and tap water continuously available and $12 \mathrm{~h}$ lighting cycles (lights on = 0700--1900 h). Mice were removed from yroup housing and injected with vehicle (.98 sodium chloride solution) or drug (aponorphine $\mathrm{HCl} 1.0$ and $2.5 \mathrm{mg} / \mathrm{kg}$; amantadine $\mathrm{HC \perp} 25.0$, $50.0,75.0 \mathrm{mg} / \mathrm{kg}$ ) using a constant $10 \mathrm{ml} / \mathrm{kg}$ volume. Five to ten minutes later subjects were individually placed in the testing apparatus for a single 15 ininute session. The apparatus was modeled after the original design of Kokkinidis and Anisman (1977, 1978) however the dimensions were increased such that each arm had a length of $30 \mathrm{cin}$, a width of $8 \mathrm{~cm}$, and a height of 10 cm. The three equal arms were juxtaposed at 120 degrees from each other, and were covered with transparent plexiglas. All testing was carried out in a sound attenuated room with background masking noise of 20 dB provided by the continuous operation of an air circulation system.

In order to control for any direct effects of drugs upon overall motor activity levels, and to equate the statistical contributions of subjects with differing basal activities, each subject was scored on a proportional rather than an absolute basis. Proportions of alternations were based upon the number of successive alternations (Fig. IA) divided by total number of alley entries. Thus, for a given subject irrespective of total activity, a score of 1.0 indicated complete response alternation, a score of .5 indicated alleys were immediately re-entered on half the total trials, and a score of less than .5 indicated predominant sensory perseveration. This measure has been shown to be reliable in previous studies (Kokkinidis and Anisman, 1977, 1978). Fata are presented as group means and standard errors. Significance was assessed using univariate randomized design analysis of variance with post-hoc comparisons by Sheffe's procedure. 
Results and Discussion

Vehicle treated rats showad high levels of successive alternation entering all three arms of the maze, and typically entering the arm which was least recently visited (Fig. 2, first column). Both drug treatments produced significant dose related reductions in this tendency. Groups showed an overall significant difference ( $F 5,40=15.3 ; p<0.0001)$, with between groups differences accounting for $69 \%$ of the conposite variance. Both the higher dose of aponorphine (Fig. 2, column 3 ) dose ( $F=59.7 ; p<.0001)$ and the higher two doses of anantadine (Fig. 2, columns 5,6$)(\mathrm{F}=11.2$, 10.6 respectively; $\mathrm{p}<.001,<.002$ ) were significantly decreased in their overall proportions of alternations in coinparison with vehicle injected controls. This suggests excessive dopamine scumulation results in pathological narrowing of attention.

The finding of a normal response bias in the untreated mouse is hardly surprising given earlier studies by Glick et al. (1977). Either of two DA active drugs, a receptor agonist or a DA releasing ajent, produced responses which could not readily be explained as motor stereotypes but which could be interpreted as sensory perseveration. This suggests the possibility that DA receptor activation is not only involved with the potentiation of prepotent behavioral patterns but in addition may be involved with an attentional process of some sort. Such involvement has been postulated by others (Ellinwood et al., 1973; Stevens, 1977); nonetheless the issue has not been widely addressed using preclinical models.

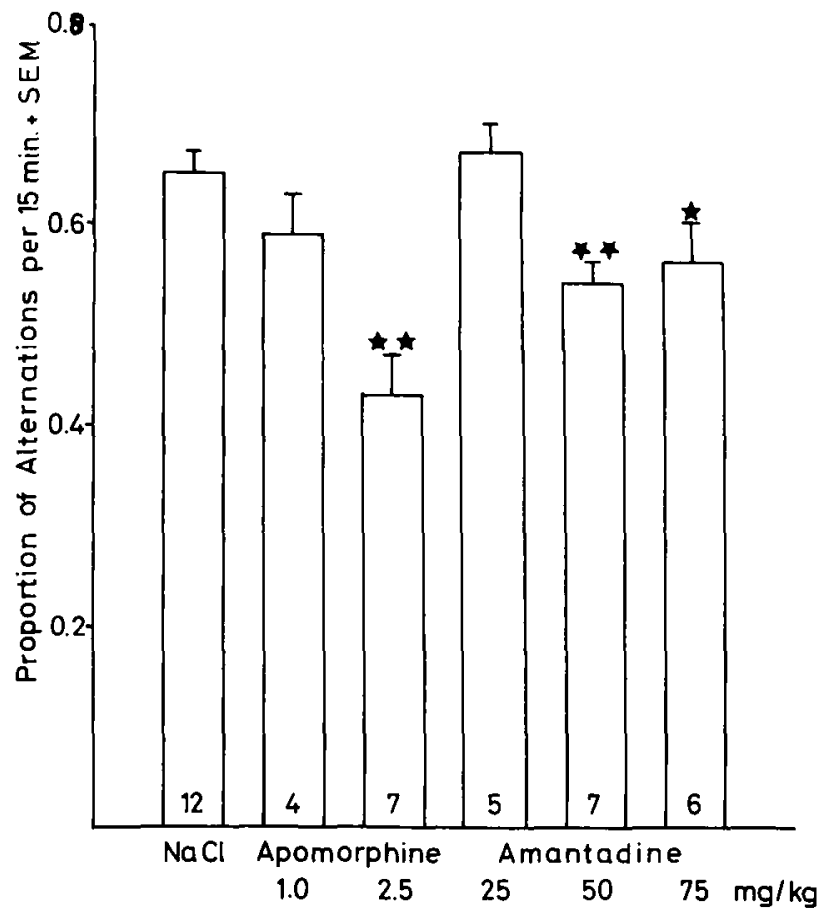

Figure 2: Normal and drug induced alternations in response patterning of mice in a Y-maze. The ordinate is a relative measure of response perseveration and represents total number of response perseverations divided by total response perseverations and alternations per subject. All data as group means and standard errors.

$\star p<.002 ; \quad \star * p<.001$ 


\section{Conclusion}

The present results, then, extend the findings of others to a novel preclinial preparation suggesting (1) a fairly broad species generality to the effects of DA upon attention, and (2) $Y$-maze performance may be a useful psycnopharmacological procedure for evaluating attentional effects. Given a continuing interest in DA involvement in schizophrenia, this may be a useful procedure for further study.

\section{References}

CARLSSON, A. (1979). Does dopanine have a role in schizophrenia. Biol. Psychiat. $13: 3-22$.

CROW, T.J., DEAKIN, J.F.W., JOHNSTONE, E.C. and LONGDEN, A. (1976). Dopamine and schizophrenia. Lancet. 563-565.

ELCINWOOD, E.H., SUDILOVSKY, A. and NELSON, L.M. (1973). Evolving behavior in the clinical and experimental amphetamine (model) psychosis. Am. J. Psychiat. 130: 1088-1093.

FOG, R. (1972). On stereotypy and catalepsy studies on the effects of amphetamines and neuroleptics in rats. Acta Neurol. Scand. 48 (suppl $50): 66$.

GLICK, S.D., ZIMMERBERG, B. and JERUSSI, T.P. (1977). Adaptive significance of laterality in the rodent. In: Evolution and Lateralization of the Brain, S.J. Dimond and D.A. Blizard (eds). Ann. NY. Acad. Sci., New York, 299: $180-186$.

ISSAC, W. (1971). A study of the relationship between the visual system and the effects of D-amphetamine. Physiol. Behav. 6: 157-159.

IVERSEN, S. (1977). Striatal function and stereotyped behavior. In: Psychobiology of the Striatum, A.R. Cools, A.H.M. Lohman, J.H.L. von den Becken (eds), pp. 99-118. North Holland Publishing Co., Amsterdam.

KOKKINIDIS, L. and ANISMAN, H. (1977). Perseveration and rotational behavior elicited by d-amphetamine in a Y-maze exploratory task: Differential effects of intraperitoneal and unilateral intraventricular injection. Psychopharmacology. 52: $123-128$.

KOKKINIJIS, L. and ANISMAN, H. (1978). Abatement of stimulus perseveration following repeated d-amphetamine treatment: Absence of behaviorally augmented tolerance. Pharmac. Biochem. Behav. 8: 557-563.

MELTZER, H.Y. and STAHL, M. (1976). The dopamine hypothesis of schizophrenia: A review. Schizophrenia Bull. 2: 19.

MIRSKY, A.F. and ORREN, M.M. (1978). Attention. In: Neuropeptide influences on the brain and behavior, L.H. Miller, C.A. Sandman and A.J. Kastin ( $2 d s$ ), pp. 233-268. Raven Press, New York.

RANDRUP, A. and MUNKVAD, I. (1967). Stereotyped activities produced by amphetamine in several animal species and man. Psychopharmacologia. $\underline{11}: 300-310$.

STEVENS, J. (1977). Striatal function and schizophrenia. In: Psychobiology of the Striatum, A.R. Cools, A.H.M. Lohman and J.H.L. van der Bercken (eds), pp. 173-194. North Holland Publishing Co., Amsterdam. 
STEVENS, J., LIVEKMORE, A. and CRONAN, J. (1977). Effects of deafening and blindfolding on amphetamine induced stereotypy in the cat. pnysiol. Behav. 18: 809-812.

Inquiries and reprint requests should be addressed to:

R. J. Katz, Mental Health Research Institute, Departinent of psychiatry, University of Michigan Medical Center, Ann Arbor, MI 48109. 